\title{
Análisis de los materiales pictóricos empleados por fray Juan Sánchez Cotán. Obras pertenecientes al Museo de Bellas Artes de Granada
}
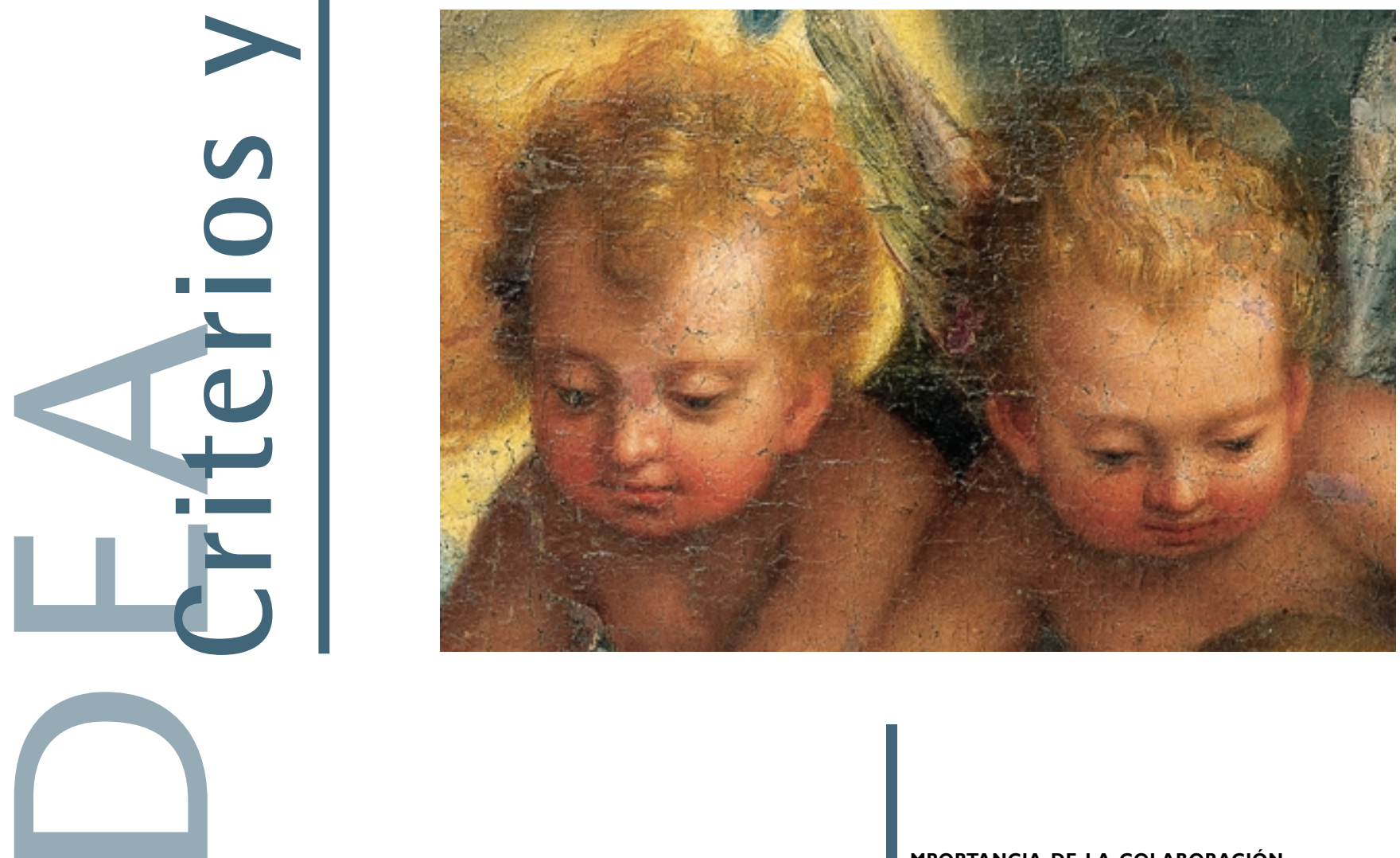

$\mathrm{M}^{\mathrm{a}}$ Luisa Alonso Corral Doctora en Bellas Artes

\section{MPORTANCIA DE LA COLABORACIÓN}

Los artículos que sobre arte se escriben tradicionalmente, no suelen tener en cuenta el estado de conservación de la obra, intervenciones o envejecimiento de los materiales. Es erróneo pensar que los bienes estudiados no han sufrido algún cambio desde su creación, o que éste carece de la relevancia necesaria para influir en su apreciación estética.

Prescindir de estos elementos, durante la investigación, puede llevar a conclusiones equivocadas, como por ejemplo en el caso de la obra de Cotán titulada "La Dolorosa", atribuida a Francisco Enríquez, pintor granadino que se ocupó de "restaurar" los cuadros en 
1838, cambiando de tal manera su aspecto que hizo pensar posteriormente que eran suyos.

Antiguamente los profesionales dedicados a conservar y restaurar el patrimonio histórico, en su mayoría, no elaboraban informes del proceso. En el mejor de los casos, como en el cuadro titulado "La Virgen despertando al Niño", se puede encontrar que de la "restauración" que se hizo en 1953, pegan en el reverso del bastidor una breve reseña de la intervención escrita a mano.

Hoy día, en ambas disciplinas, los profesionales están corrigiendo estos fallos poco a poco, con la introducción progresiva de Métodos Científicos y la realización de investigaciones en colaboración con Químicos, Físicos, Biólogos, Geólogos, etc.

En este proceso de evolución y difusión se considera el estudio del arte como una ciencia integradora, es decir, que incorpora métodos nuevos sin dejar de lado los tradicionales, línea seguida en mi tesis, tomando la obra de fray Juan Sánchez Cotán como ejemplo.

El por qué de este pintor y no otro es sencillo, siendo sus bodegones obras de talla internacional, su producción religiosa está infravalorada por los estudiosos del arte, salvo excepciones como el profesor Orozco, que escribe sobre su vida y cataloga sus obras (1993, libro monográfico sobre Cotán).

La tendencia general es considerarlas como una "paradoja" frente a la gran calidad de los bodegones, ignorando las consecuencias negativas que su mal estado de conservación aporta sobre la apreciación estética final del cuadro.

Analizar los 53 cuadros pertenecientes al Museo de Bellas Artes de Granada desde un ángulo más técnico, incorporando el punto de vista del investigador actual contrastando documentos y datos analíticos, para aportar otros nuevos, es la meta del método seguido, que a continuación veremos.

\section{ESTUDIO HISTÓRICO}

Tanto la revisión bibliográfica sobre el tema, como el estudio de documentos, catálogos, informes de restauración, fichas y archivos de la época, son la base inicial de toda investigación. El objetivo es conocer lo que existe antes de pretender, en el mejor de los casos, aportar algo nuevo sobre el tema.

Sobre Sánchez Cotán se conocen documentos tan importantes como su partida de Bautismo (25 de junio de 1560), y la de sus tres hermanos, que nos sirven para elaborar su árbol genealógico.

Otros documentos de especial relevancia para elaborar su biografía, son el Testamento ( 10 de agosto de 1603), paso previo a su ingreso como postulante en la Cartuja de Granada, el Inventario de sus bienes

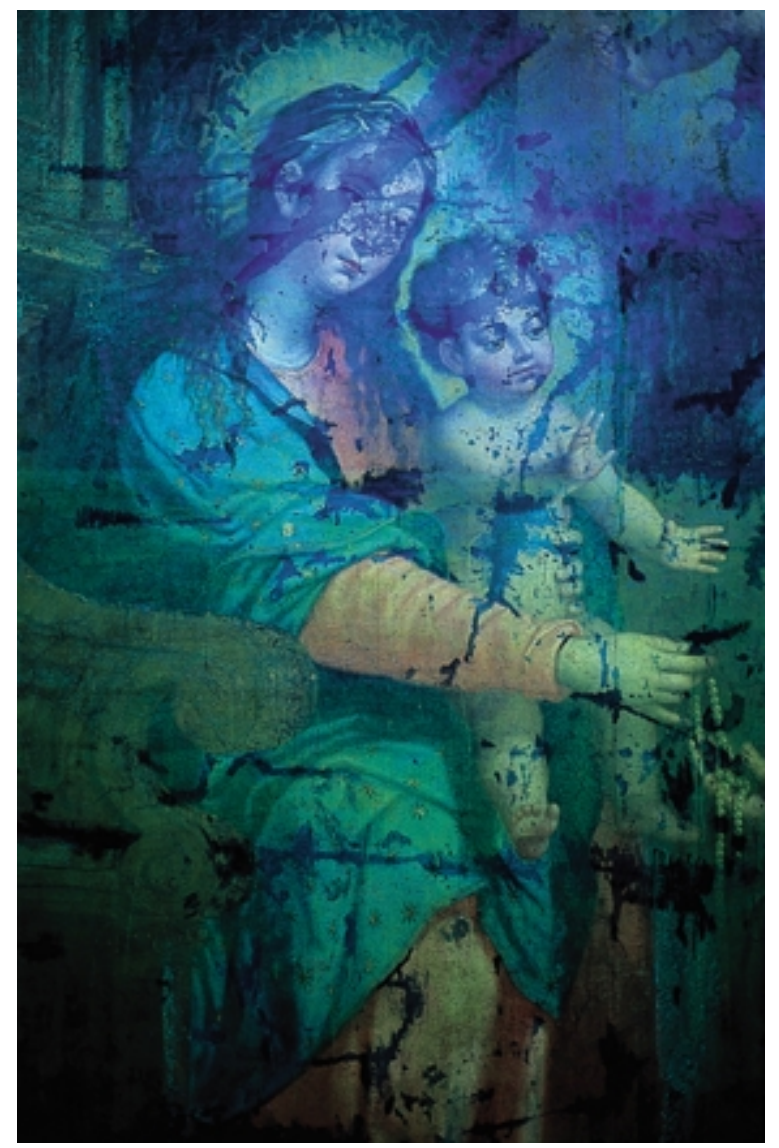

$\varangle$
L "Aparición de la Virgen del Rosario a San Bruno". Fray Fotografía con luz ultravioleta. Sánchez de Cotán
( 3 de agosto de 1603) y el informe de limpieza de sangre (29 de julio de 1604), que se hace para este mismo fin.

Por medio de historiadores coetáneos suyos se conocen otras fechas y anécdotas como que muere el 8 de septiembre de 1627, el mismo día de su ingreso o que se autorretrató en el cuadro titulado "La aparición de la Virgen del Rosario a San Bruno".

El conocimiento del ambiente histórico y social de los siglos $\mathrm{XVI}$ y $\mathrm{XVII}$, así como los procedimientos pictóricos y la elaboración de un cuadro de pigmentos empleados en su tiempo, son datos que sirven como referencia a los análisis posteriores.

\section{Historia MATERIAL de LAS ObRAS}

La recopilación de fotos antiguas de los cuadros, fichas museográficas y cualquier noticia relacionada con ellos o el lugar donde estuvieron ubicados desde que se pintaron hasta nuestros días, es una información muy valiosa para entender su estado de conservación.

El lugar geográfico donde ha estado situada o sea el análisis medio ambiental de las condiciones de humedad, temperatura y contaminación, junto con el trato recibido por parte del hombre, son factores que repercuten en su estética y conservación. 


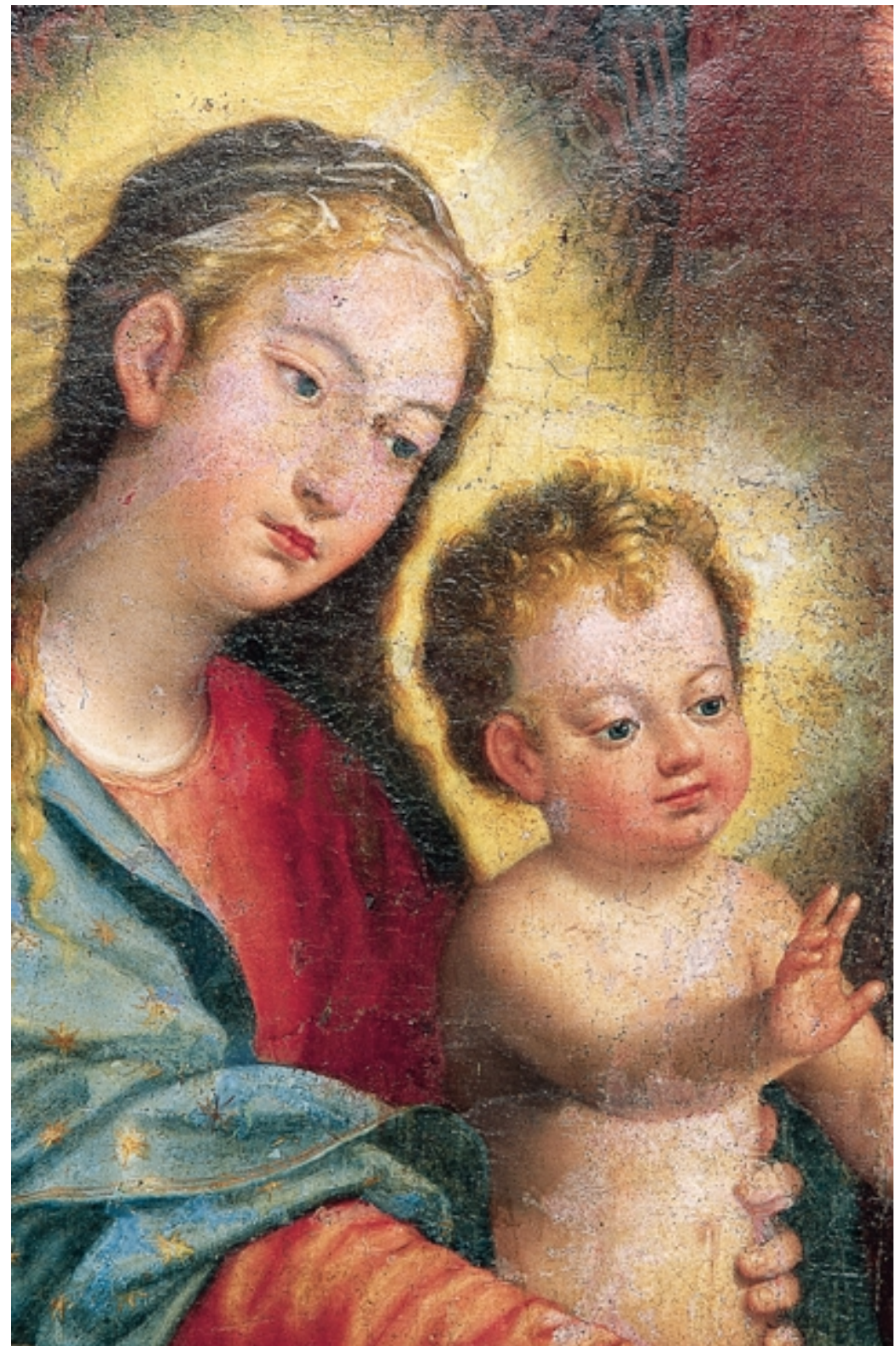

2. "La aparición de la Virgen del Rosario a San Bruno" Fray Sánchez de Cotán. Detalle.
Y en el caso de las que actualmente se encuentran depositadas en la Cartuja, que presentan el peor estado de conservación, se sabe que sirvieron para decorar los altares de la plaza de Bibarrambla en las fiestas del Corpus devolviéndolas sin moldura y estropeadas ya en 1839.

Recopilando las noticias de los catálogos y fichas de los archivos del Museo, se puede elaborar un cuadro de las restauraciones. Las operaciones que se realizan consisten en forrados, recolocación de bastidores y marcos, limpieza, reintegración y barnizado de las obras.

\section{ELABORACIÓN DE FICHAS}

Una vez recopilados todos los datos posibles y elaborados los cuadros citados, se deben reflejar y actualizar los mismos, en fichas personales que nos ayudan posteriormente en el análisis de los datos técnicos. Esta información se comprueba, complementa y corrige con la observación de las obras in situ.

En las fichas que para el catálogo elaboré, los apartados que hice fueron los siguientes: título/s, números y medidas dadas en los distintos catálogos, técnica, procedencia, época, datos sobre el marco, ubicación en el momento del estudio, estado de conservación e intervenciones sufridas, descripción, obras con la misma temática en el apartado "otros", exposiciones, bibliografía, muestras tomadas y fotografías.

\section{REALIZACIÓN DE FOTOGRAFíAS}

Las fotografías se emplean en el campo del arte para conservar las imágenes de las obras en sustitución del grabado a partir de 1839. Demostrando ser el medio más útil para controlar el estado de conservación de las obras, permitiendo obtener imágenes objetivas, ya sean en $\mathrm{BN}$, color o mediante diapositivas.

Actualmente, en el campo de la conservación, se realizan fotografías con radiaciones, electromagnéticas distintas de las habituales con luz visible. Se trata de longitudes de onda por encima de los 750 nm (I.R.) y por debajo de los 400nm (U.V. y R.X.). Su capacidad de penetración es mayor, con lo que se consiguen imágenes de las capas subyacentes, obteniendo información muy valiosa a la hora de proceder a la restauración de la obra.

Las fotografías tomadas a los cuadros de Cotán fueron con luz visible en BN y a color, generales para el catálogo. Y para el informe sobre su estado de conservación, fotografías de detalles y fotomicrografías de los daños. El empleo de luz rasante para obtener el relieve de la superficie pictórica aportó datos muy interesantes sobre su conservación.

Se realizaron pruebas con I.R., U.V. y Rayos X, pero las condiciones de luz del Museo y el gran tamaño de las 
obras, que impedía su traslado a un lugar más adecuado para su estudio, hicieron que los resultados obtenidos fueran poco fiables.

\section{TOMA DE MUESTRAS}

Una vez catalogados y fotografiados los cuadros se procede a la extracción de fragmentos de tejido y materia pictórica de las obras. Las muestras extraídas se referencian con un primer número que identifica la obra en el catálogo seguido de una letras que indica la tonalidad; a-azul, b-blanco, r-rojo, etc.

El lugar de donde se ha cogido la muestra se marca en un croquis del cuadro, que tomando como referencia las fotografías realizadas con anterioridad, se emplea también para señalar y elaborar el informe de los daños.

La selección de las obras a muestrear fue exhaustiva, tratando de elegir la mayor cantidad de pigmentos distintos de cada una de ellas, e intentando abarcar todos los cuadros que por su ubicación y conservación lo permitieran, causando el mínimo daño posible a la misma. Teniendo en cuenta estos criterios fue posible la toma de micromuestras de once obras. En total el número de muestras analizadas fueron cuarenta.

La preparación de las muestras -láminas delgadas- se realizó en los laboratorios de la Facultad de Geológicas de Granada, y su estudio posterior, por microscopía óptica y electrónica, en el Centro de Instrumentación Científica de esta misma Universidad.

\section{ANÁlisis QUímICOS. \\ MicROSCOPÍA ÓPTICA Y ELECTRÓNICA}

Dentro de los análisis por Microscopía óptica realizados, se diferencian dos grupos:

El primero consiste en el estudio de los tipos de tejidos empleados, identificando las fibras que los constituyen. En los casos estudiados las fibras eran en su mayoría de cáñamo, y de lino en menor proporción.

El análisis del tejiido fue posible en aquellos cuadros en que a través de las lagunas era posible ver la tela original por el anverso de la pintura, ya que prácticamente todos están forrados, lo que hace imposible su observación por el reverso.

Se trata de tejidos de diseño, fabricados en telares manuales, lo que supone un ancho máximo de un metro. Los hilos se entrecruzan formando unas veces rombos (lienzo) y otras líneas diagonales (sarga). En estos siglos las Alpujarras eran famosas en toda España por la fabricación de tejidos confeccionados con seda, cáñamo y en menor medida lino.

Y el segundo grupo de análisis por Microscopía óptica, es el de las micromuestras estratigráficas, realizado pa- ra la identificación cualitativa de pigmentos y cargas. Las imágenes que se ven en el microscopio, con distintos tipos de luz, se recogen en fotografías y diapositivas para su posterior estudio. El análisis de aglutinantes no se pudo hacer por carecer el C.I.C. de los patrones necesarios para ello.

Los análisis de las muestras inorgánicas con Microscopio electrónico de barrido fueron semicuantitativos, y se emplearon para confirmar o aclarar los resultados

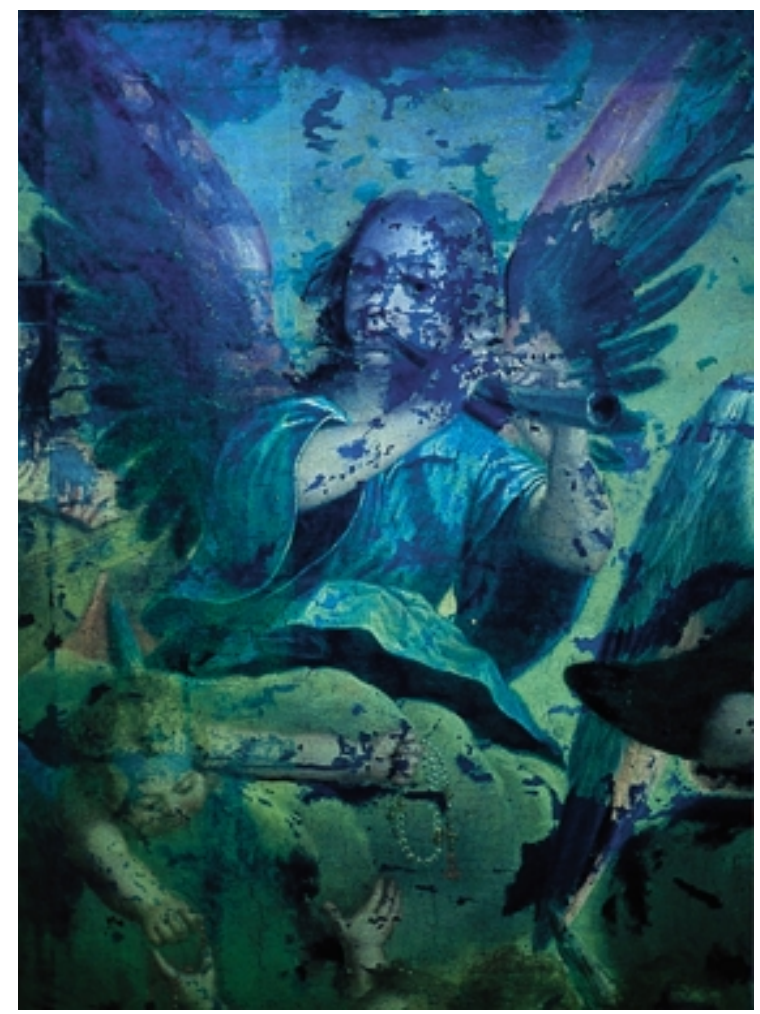

3. "Aparición de la Virgen del Rosario a San Bruno". Fotografía con luz ultravioleta. obtenidos a través de la observación de las muestras por microscopía óptica. Con este método instrumental se realizaron microanálisis por dispersión de energía, previa metalización de las mismas.

Su funcionamiento técnico consiste en bombardear la superficie de la muestra con un haz de electrones dando lugar a la emisión de rayos $X$, entre otras señales, característicos de cada elemento. Los rayos $X$ se transforman mediante detectores en fotones, que son separados según su energía, dando lugar a un espectro.

En el espectro la posición de los diferentes picos está ligada a la energía característica de los fotones del elemento químico emisor analizado. La altura del pico es función del contenido de este elemento en el analítico. 